\title{
Heavy Metals in Marine Surface Sediments of Daya Bay, Southern China: Spatial Distribution, Sources Apportionment, and Ecological Risk Assessment
}

\section{OPEN ACCESS \\ Edited by: \\ Xiaoping Huang, \\ South China Sea Institute of \\ Oceanology (CAS), China \\ Reviewed by: \\ Gang Hou, \\ Fisheries College, \\ Guangdong Ocean University, China \\ Anglu Shen, \\ Shanghai Ocean University, China \\ ${ }^{*}$ Correspondence: \\ Huaxue Liu \\ liuhuaxue@scies.org \\ Honghui Huang \\ huanghh@scsfri.ac.cn \\ Specialty section: This article was submitted to Conservation and Restoration \\ Ecology, \\ a section of the journa \\ Frontiers in Environmental Science}

Received: 09 August 2021 Accepted: 04 November 2021

Published: 17 December 2021

Citation:

Wang H, Fan Z, Kuang Z, Yuan Y, Liu H and Huang $H$ (2021) Heavy Metals in

Marine Surface Sediments of Daya

Bay, Southern China: Spatial

Distribution, Sources Apportionment,

and Ecological Risk Assessment.

Front. Environ. Sci. 9:755873.

doi: 10.3389/fenvs.2021.755873
Huijuan Wang ${ }^{1,2}$, Zhengqiu Fan ${ }^{3}$, Zexing Kuang ${ }^{1,2}$, Yuan Yuan ${ }^{3}$, Huaxue Liu ${ }^{2 *}$ and Honghui Huang ${ }^{1 *}$

\footnotetext{
${ }^{1}$ Key Laboratory of Fishery Ecology and Environment, South China Sea Fisheries Research Institute, Chinese Academy of Fishery Sciences, Guangzhou, China, ${ }^{2}$ South China Institute of Environmental Science, Ministry of Ecology and Environment, Guangzhou, China, ${ }^{3}$ Department of Environmental Science and Engineering, Fudan University, Shanghai, China
}

Daya Bay, especially in the northwestern region, which is a nature reserve with larval economic fish and shrimp populations, is no longer an unpolluted marine environment due to the recent increases in anthropogenic activities. This study collected seasonal surface sediment samples from 20 sites in northwestern Daya Bay to evaluate pollution and ecological risks and to identify possible sources and transport pathways of heavy metals ( $\mathrm{Cd}, \mathrm{Pb}, \mathrm{Cr}, \mathrm{Cu}, \mathrm{Zn}, \mathrm{Hg}$, As). The results showed that all the heavy metal concentrations were below the established primary standard criteria, except for concentrations of $\mathrm{Cr}$ in spring, as well as $\mathrm{Cu}$ and $\mathrm{Zn}$ in autumn at several sampling stations, which had excess rates of $35,4.76$, and $4.76 \%$, respectively. The geoaccumulation index (Igeo) values of heavy metals indicated that all sites had unpolluted to moderate pollution levels. In comparison to the samples collected in autumn, those in spring experienced a higher degree of pollution, particularly $\mathrm{Cr}$ and As. The ecological risk indices of heavy metals in sediments ranged from 225.86 to 734.20 in spring and from 196.69 to 567.52 in autumn, suggesting that most sites had a moderate ecological risk or a considerable ecological risk, and very few a had high ecological risk. Moreover, ArcGIS10.2 software was used to visualize their spatial distribution, and the results were similar in both spring and autumn. The results of the Pearson correlation analysis and principal component analysis showed that $\mathrm{Cu}, \mathrm{Hg}$, and $\mathrm{Pb}$ might be affected by anthropogenic activities, and As might be derived from natural sources such as atmospheric inputs. A cluster analysis showed that heavy metals were mainly affected by the negative impacts of human beings on the environment.

Keywords: heavy metals, marine surface sediments, sources apportionment, ecological risk assessment, daya bay 


\section{INTRODUCTION}

Surface sediments are a significant component of aquatic environments. In many areas, the heavy metals in the surface sediment are gradually increasing and have become a growing topic of interest worldwide (Ranjbar Jafarabadi et al., 2017; Nel et al., 2020). This is because of their enrichment, nonbiodegradability, or long biological half-life, as well as their inherent toxicity, extensive sources, biogeochemical recycling, and ecological risks (Ranjbar Jafarabadi et al., 2017; Shakouri and Gheytasi, 2018; Xu et al., 2018). Most heavy metals are incorporated into the sediment once they enter the marine environment. Therefore, sediments are considered a source of metals, and they also record anthropogenic impacts (Kang et al., 2017). With rapid industrial and economic development, many coastal bays are subjected to severe heavy metal pollution arising from anthropogenic activities (Qian et al., 2014; Lu et al., 2017; Zhang P. et al., 2017; Liang et al., 2018; Pan et al., 2020).

Marine conservation areas are intertidal or subtidal environments and encompass the overlying water, other geographical features (such as the coast, estuary, wetlands, and islands), and associated flora and fauna (Ervin et al., 2010; Gaines et al., 2010; Zhang Y. et al., 2017). Marine protected areas are of great significance in the protection of biodiversity and can enhance ecological function and reduce the decline of marine biomass (Ervin et al., 2010). The "Baguang-Aotou-Xiachong" area of Daya Bay, which acts as a buffer zones between the land and the sea, is vulnerable to natural processes and anthropogenic activities. Since the 1980s, there have been large-scale anthropogenic activities along the coastline, such as mariculture, ports, nuclear power stations, and petrochemical industries (Yu et al., 2010; Gu et al., 2016). Various kinds of pollution enter Daya Bay, causing serious heavy metal contamination.

The source, migration, transformation, and destination of heavy metals are hot topics in the study of sedimentary environments. Rivers are an important nonpoint source of pollution and have attracted much research attention. There are five main rivers in northwestern Daya Bay, namely, the Danao River, the Zao River in the south, the Yanqian River, the Baigang River, and the Xiayong River. The upstream industries on these rivers are intensive and include processing and metal industries. Although there have been several previous studies on heavy metal contamination in Daya Bay in recent years, these studies mainly investigated the present situation of heavy metal pollution in the bay as a whole (Yu et al., 2010; Zhao et al., 2016), and there was no specific research on the effects of terrestrial pollutants on heavy metals in marine surface sediments. Most previous researchers divided heavy metal pollution sources into either natural or anthropogenic (Lu et al., 2017; Lü et al., 2018) and lacked a specific relationship between the heavy metals and the sampling stations. Moreover, the effect of sewage outfall on marine protected areas was ignored when identifying heavy metal sources. Therefore, the objectives of this study were as follows: 1) to study the spatial distribution of heavy metals in the Daya Bay area based on the GIS interpolation method; 2) to estimate the degree of heavy metal contamination using the geoaccumulation index $\left(I_{\text {geo }}\right)$ and potential ecological risk index $(R I)$; and 3$)$ to identify the sources and transport pathways of heavy metals.

\section{MATERIALS AND METHODS}

\section{Study Area and Sample Collection}

Daya Bay (latitude $22^{\circ} 25^{\prime} \sim 22^{\circ} 50^{\prime} \mathrm{N}$, longitude $114^{\circ} 30^{\prime} \sim 114^{\circ} 55^{\prime} \mathrm{E}$ ) has a subtropical climate, high temperatures, rainy conditions, and the prevailing monsoon dominates. It is a submerged valley in a mountainous area, which is more than $30 \mathrm{~km}$ from south to north. The gulf of Daya Bay has the characteristics of a subsidence mountain coast. The seabed topography of Daya Bay gradually deepens from the top of the bay, with an average depth of $11 \mathrm{~m}$. The study area includes areas of petrochemical industrial, ports, seawater aquaculture, and densely populated towns. It can be used as a typical study area for the effects of human activities on heavy metal pollution in Daya Bay.

The research area, also known as the Baguang-Aotou-Xiayong area, is located on the northwestern side of Daya Bay. Twenty surface sediment samples were collected in the bay in late spring (April) and early autumn (September) of 2016 (Figure 1).

\section{Analytical Methods}

Sediment samples were collected using an oceanic 50 mud collector. For each sample, the top $5 \mathrm{~cm}$ of sediment was sampled. The samples were placed in precleaned polyethylene bags and stored at $4^{\circ} \mathrm{C}$ in the laboratory until analysis.

The sediment samples were freeze-dried. Decomposition of the sample was performed through ultrasonic oscillation before instrumental measurement. Grain size samples were analyzed using the laser diffraction method (Mastersizer2000 Malvern, United Kingdom). The measurement scope of the appliance was $0.02-2000 \mu \mathrm{m}$, and the relative error of repeated measurements was less than 3. A sieve analysis method was used for particle sizes larger than $2000 \mu \mathrm{m}$. Dried and homogenized samples were analyzed using microwave digestion. After weighing $0.3 \mathrm{~g}$ of each sample in a high-pressure Teflon bomb, $8 \mathrm{ml}$ concentrated $\mathrm{HNO}_{3}(65 \%)$ and $2 \mathrm{ml} \mathrm{H}_{2} \mathrm{O}_{2}$ (30\%) were added. The sample was covered with a watch glass for $24 \mathrm{~h}$ to prevent interference. Samples were then digested using the Ethos Plus microwave laboratory station (Milestone, Sorisole, Italy) with the following temperature stages, all at $1000 \mathrm{~W}: 30-200^{\circ} \mathrm{C}$ for $15 \mathrm{~min}$, $200^{\circ} \mathrm{C}$ for $40 \mathrm{~min}$, followed immediately by ventilation at room temperature for $18 \mathrm{~min}$. Extracts were then transferred into $50 \mathrm{ml}$ flasks and heated until $1 \mathrm{ml}$ remained. After cooling, the concentrated extract was diluted to $5 \mathrm{ml}$ with ultrapure water and mixed well.

The concentrations of mercury $(\mathrm{Hg})$ and arsenic (As) were measured with an atomic fluorescence (AFS, 830, Hitachi, Japan). Copper $(\mathrm{Cu})$, lead $(\mathrm{Pb})$, cadmium $(\mathrm{Cd})$, and chromium $(\mathrm{Cr})$ in the sediments were determined with flame free atomic absorption spectrometry (AAS, Z2000, Hitachi, Japan), and zinc (Zn) by flame atomic absorption spectrometry (AAS, Z2000, Hitachi, Japan). 


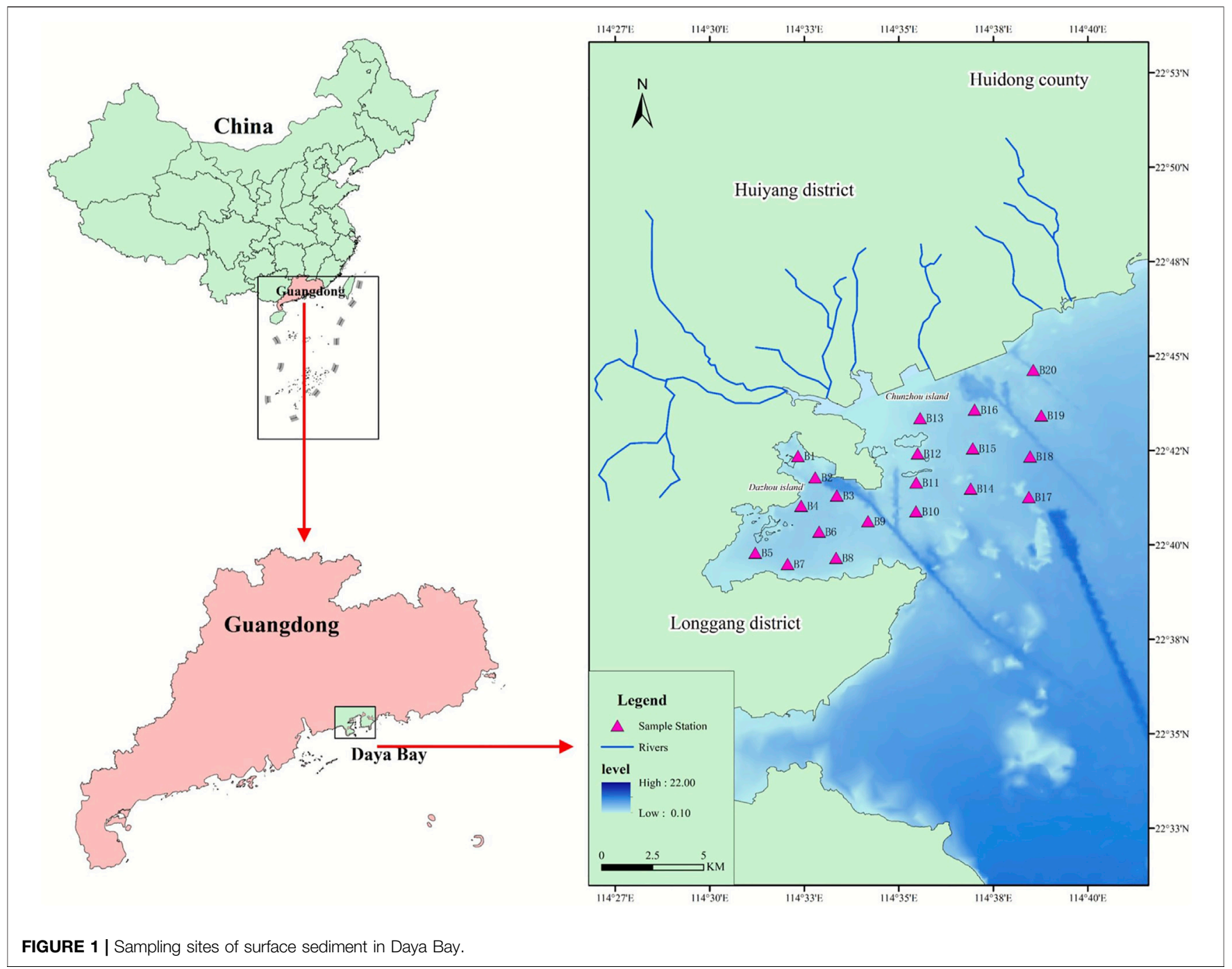

\section{Quality Assurance and Quality Control}

The quality assurance of the analytical process for the dissolving heavy metals in the sediments was implemented using the methods released by the National Research Center for standard GB17378-2007. Each sample was measured three times or more to determine the precision and accuracy. The measured blank values were not greater than the corresponding method detection limit. In addition, the deviation of these values was less than $6 \%$ in all analyses. Before operation, all applied glassware (bottles, tubes, etc.) in the lab were soaked with $10 \%$ $\mathrm{HNO}_{3}(\mathrm{w} / \mathrm{w})$ for more than 2 days and rinsed in deionized water.

\section{Evaluation of Heavy Metals Contamination Geoaccumulation Index}

The useful and common index to define and estimate metal contamination in sediment (Müller, 1979) is the geoaccumulation index (Igeo). It is defined as:

$$
I_{\text {geo }}=\log _{2}\left(\frac{C_{i}}{1.5 B_{i}}\right)
$$

where $C_{i}$ stands for the concentration of the examined metal $i$ and $B_{\mathrm{i}}$ stands for the geochemical background concentration of the metal $i$ (Zhang, 1991). The selection of background value is an important aspect in the assessment of pollution status (Naifar et al., 2018). Factor 1.5 stands for the background matrix correction factor because of lithogenic effects (Müller, 1979). The $I_{\text {geo }}$ values are divided into the following 7 categories: unpolluted level $(<0)$; unpolluted to moderate level $(0-1)$; moderate level (1-2); moderate to strong level (2-3); strong level (3-4); strong to extremely strong level (4-5); extreme level $(>5)$.

\section{Single Pollution Indices $\left(\boldsymbol{C}_{f}\right)$}

The $C_{f}$ is a commonly used index to evaluate the degree of contamination for sediments in aquatic ecosystems and to reveal the contamination level for an individual metal (Loska et al., 1997). Its calculation is shown with equation below:

$$
C_{f}^{i}=\frac{C_{i}}{B_{i}}
$$



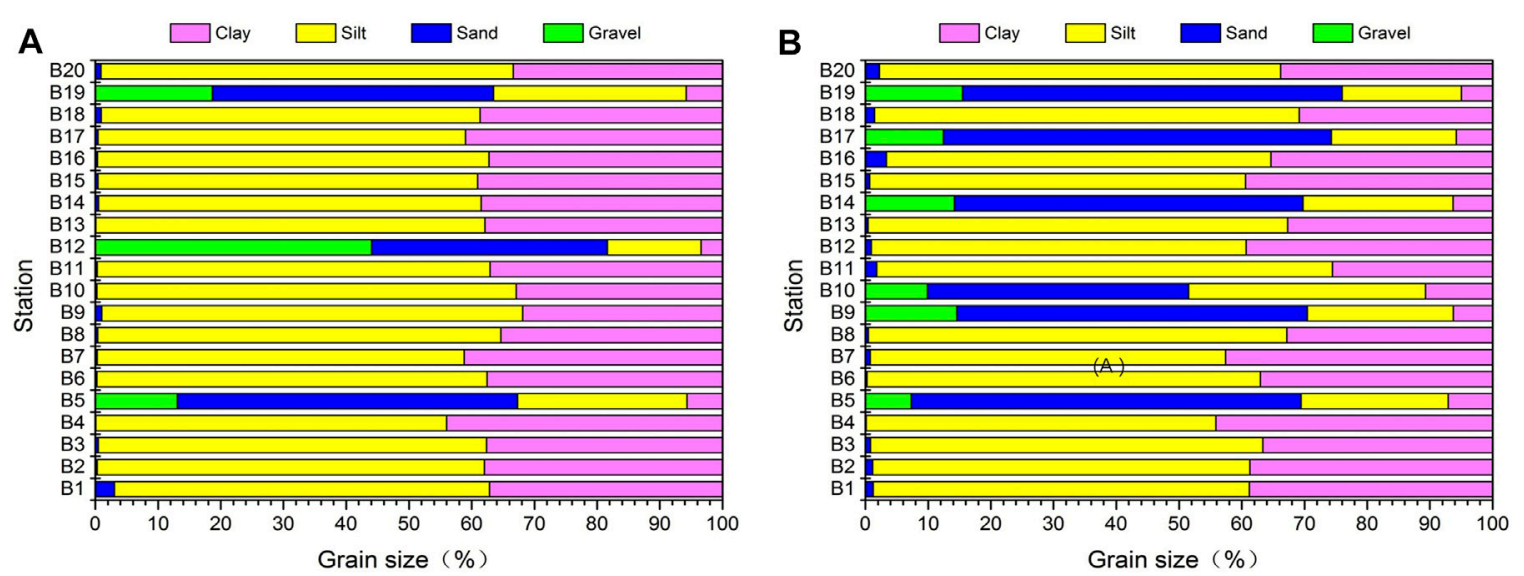

FIGURE 2 | The grain size of surface sediment in Daya Bay in spring (A) and autumn (B).

where $C_{i}$ is the concentration of the examined metal $i$ and $B_{i}$ is the geochemical background concentration of the metal $i$.

\section{Potential Ecological Risk Index (RI)}

To explore ecological risk in the heavy metals, the $R I$ index is introduced (Hakanson, 1980), and its calculation formula is as follows:

$$
\begin{aligned}
R I=\sum_{i=1}^{n} E_{r}^{i} & =\sum_{i=1}^{n} T_{r}^{i} \times C_{f}^{i} \\
C_{f}^{i} & =\frac{C_{s}^{i}}{C_{n}^{i}}
\end{aligned}
$$

where $E_{r}^{i}$ stands for the potential ecological risk factor for each heavy metal, and $T_{r}^{i}$ stands for the toxic-response factor for individual heavy metal $i$. The toxic response factors for $\mathrm{Cu}$, $\mathrm{Pb}, \mathrm{Zn}, \mathrm{Cd}, \mathrm{Cr}, \mathrm{Hg}$, and $\mathrm{As}$ are 5, 5, 1, 30, 2, 40, and 10, respectively (Hakanson, 1980). The $R I$ is divided into 4 categories: (Hakanson, 1980): <150 (low ecological risk), $150 \leq R I<300$ (moderate ecological risk), $300 \leq R I<600$ (considerable ecological risk), and $>600$ (very high ecological risk). $C_{f}^{i}$ is the contamination factor for individual examined metal $i, C_{s}^{i}$ stands for measured actual concentration for metal $i$ in the surface sediment, and $C_{n}^{i}$ is the background value for metal $i$.

\section{Statistical Analysis and Geochemical Mapping}

The data normality was assessed by the Kolmogorov-Smirnov and Shapiro-Wilk normality tests. Additionally, Pearson correlation analysis, principal component analysis (PCA), and cluster analysis (CA) were conducted in SPSS 22.0 and R3.2.2 to explore the possible sources of the heavy metal elements and their relevance to other metals, respectively. Ultimately, the Kriging interpolation method was introduced to interpolate the values of the calculated indices and heavy metals concentration (Karim and Williams, 2015; Tian et al., 2017), which revealed the visualization of the heavy metal index and their spatial distribution by ArcGIS10.2 software.

\section{RESULTS AND DISCUSSION}

\section{Concentration of the Heavy Metals in Marine Surface Sediments of Daya Bay}

As shown in Figure 2, the grain size of the surface sediment at each station was quite different. Generally, the surface sediments were primarily composed of silt and clay in spring and autumn with mean sizes of $6.78 \varphi$ and $6.18 \varphi$, respectively. The percentage of silt varied between 14.94 and $67.10 \%$, and the percentage of clay ranged from 3.42 to $44.02 \%$ in spring. Similarly, the percentage of silt varied between 18.98 and $78.66 \%$, and the percentage of clay ranged from 5 to $44.12 \%$ in autumn. The results showed that the average grain size in spring was smaller than that in autumn.

The average amount of organic carbon in autumn was lower than that in spring (Table 1), and the decomposition of total organic carbon was closely related to the migration and transformation of heavy metals in sediments.

As shown in Table 1, the concentrations of $\mathrm{Cd}, \mathrm{Pb}, \mathrm{Cr}, \mathrm{Cu}, \mathrm{Zn}$, $\mathrm{Hg}$, and As were 0.07-0.42, 28-55, 62-101, 13-82, 79-141, $0.01-0.07$, and $6.7-11 \mathrm{mg} / \mathrm{kg}$ in spring, respectively. Moreover, in autumn, the respective concentration ranges for individual heavy metals were as follows: $\mathrm{Cd}, 0.05-0.27 \mathrm{mg} / \mathrm{kg} ; \mathrm{Pb}$, $24-49 \mathrm{mg} / \mathrm{kg} ; \quad \mathrm{Cr}, \quad 24-62 \mathrm{mg} / \mathrm{kg} ; \mathrm{Cu}, \quad 12-35 \mathrm{mg} / \mathrm{kg} ; \mathrm{Zn}$, 90-182 mg/kg; Hg, $\quad 0.02-0.06 \mathrm{mg} / \mathrm{kg} ; \quad$ As, $\quad 6.9-8.6 \mathrm{mg} / \mathrm{kg}$. According to their average concentrations, the examined metals in the sampled sediment can be arranged in the following order for both spring and autumn: $\mathrm{Zn}>\mathrm{Cr}>\mathrm{Pb}>$ $\mathrm{Cu}>\mathrm{As}>\mathrm{Cd}>\mathrm{Hg}$. Except for $\mathrm{Hg}$ and $\mathrm{Zn}$ being equal, the mean concentrations were higher in spring than in autumn for individual heavy metals. Additionally, the coefficients of variation (CVs) of the heavy metals in spring were 58.08, $17.59,11.93,53.19,13.76,39.68$, and $12.10 \%$, respectively. Correspondingly, the heavy metal CVs in autumn were 
TABLE 1 | Descriptive statistics of heavy metal concentrations in surface sediments (mg/kg) in Daya Bay.

\begin{tabular}{|c|c|c|c|c|c|c|c|c|c|c|}
\hline \multirow[t]{2}{*}{ Element } & \multicolumn{5}{|c|}{ Spring } & \multicolumn{5}{|c|}{ Autumn } \\
\hline & Min & Max & Mean & SD & CV (\%) & Min & Max & Mean & SD & CV (\%) \\
\hline $\mathrm{Cd}$ & 0.07 & 0.42 & 0.13 & 0.08 & 58.08 & 0.05 & 0.27 & 0.10 & 0.06 & 57.55 \\
\hline $\mathrm{Pb}$ & 28.00 & 55.00 & 41.95 & 7.38 & 17.59 & 24.00 & 49.00 & 38.75 & 6.01 & 15.50 \\
\hline $\mathrm{Cr}$ & 62.00 & 101.00 & 79.55 & 9.49 & 11.93 & 24.00 & 62.00 & 52.90 & 8.25 & 15.60 \\
\hline $\mathrm{Cu}$ & 13.00 & 82.00 & 27.35 & 14.55 & 53.19 & 12.00 & 35.00 & 23.25 & 6.82 & 29.33 \\
\hline $\mathrm{Zn}$ & 79.00 & 141.00 & 116.25 & 16.00 & 13.76 & 90.00 & 182.00 & 116.25 & 21.83 & 18.78 \\
\hline $\mathrm{Hg}$ & 0.01 & 0.07 & 0.04 & 0.02 & 39.68 & 0.02 & 0.06 & 0.04 & 0.01 & 38.20 \\
\hline As & 6.70 & 11.00 & 8.59 & 1.04 & 12.10 & 6.90 & 8.60 & 7.69 & 0.60 & 7.79 \\
\hline TOC & 1.23 & 3.15 & 1.88 & 0.37 & 19.68 & 1.50 & 2.50 & 1.80 & 0.28 & 15.56 \\
\hline TS & 21.80 & 388.00 & 98.37 & 92.46 & 93.99 & 10.10 & 420.00 & 156.76 & 127.52 & 81.35 \\
\hline
\end{tabular}

\begin{tabular}{|c|c|c|c|c|c|c|c|c|c|}
\hline Location & Season & Cd & $\mathrm{Pb}$ & $\mathrm{Cr}$ & $\mathrm{Cu}$ & $\mathrm{Zn}$ & $\mathrm{Hg}$ & As & References \\
\hline Study area & Spring & $0.13 \pm 0.08$ & $41.95 \pm 7.38$ & $79.55 \pm 9.47$ & $27.35 \pm 14.55$ & $116.25 \pm 16.00$ & $0.04 \pm 0.02$ & $8.59 \pm 1.04$ & - \\
\hline- & Autumn & $0.10 \pm 0.06$ & $38.75 \pm 6.01$ & $52.90 \pm 8.25$ & $23.25 \pm 6.82$ & $116.25 \pm 21.83$ & $0.04 \pm 0.01$ & $7.69 \pm 0.60$ & - \\
\hline Daya Bay, China & - & $0.07 \pm 0.02$ & $37.01 \pm 8.47$ & $59.03 \pm 16.62$ & $16.46 \pm 6.34$ & $87.81 \pm 26.43$ & $0.04 \pm 0.01$ & $8.16 \pm 1.99$ & $\begin{array}{l}\text { Zhao et al. } \\
(2016)\end{array}$ \\
\hline South China Sea & - & $0.40 \pm 0.40$ & $23.6 \pm 8.9$ & $105 \pm 86$ & $38.1 \pm 24.6$ & $87.4 \pm 47.7$ & ND & ND & $\begin{array}{l}\text { Zhu et al. } \\
\text { (2011) }\end{array}$ \\
\hline $\begin{array}{l}\text { Zhelin Bay, South } \\
\text { China }\end{array}$ & - & $0.063 \pm 0.30$ & $35.69 \pm 11.96$ & $23.07 \pm 9.27$ & $7.95 \pm 4.11$ & $74.95 \pm 9.79$ & ND & ND & $\mathrm{Gu},(2017)$ \\
\hline $\begin{array}{l}\text { Mai Po Marshes } \\
\text { Nature Reserve, } \\
\text { Hong Kong }\end{array}$ & - & $1.05 \pm 0.823$ & $52.6 \pm 12.2$ & $22.4 \pm 7.86$ & $42.8 \pm 16.7$ & $149 \pm 53.6$ & ND & ND & $\begin{array}{l}\text { Liang and } \\
\text { Wong, (2003) }\end{array}$ \\
\hline $\begin{array}{l}\text { Beibu Bay, South } \\
\text { China Sea }\end{array}$ & - & $0.16 \pm 0.05$ & $27.99 \pm 8.69$ & $53.65 \pm 19.73$ & $58.26 \pm 20.17$ & $67.28 \pm 26.56$ & $0.06 \pm 0.03$ & $9.53 \pm 3.99$ & $\begin{array}{l}\text { Dou et al. } \\
\text { (2013) }\end{array}$ \\
\hline $\begin{array}{l}\text { Mangrove- } \\
\text { aquaculture } \\
\text { wetland in } \\
\text { Shenzhen }\end{array}$ & - & $0.187 \pm 0.053$ & $46.6 \pm 9.88$ & $50.8 \pm 13.3$ & $34.54 \pm 16.4$ & $137 \pm 51.6$ & ND & $16.43 \pm 3.33$ & $\begin{array}{l}\text { Feng et al. } \\
(2017)\end{array}$ \\
\hline Background value & - & 0.027 & 21.97 & 22.35 & 6.44 & 21.67 & 0.011 & 2.61 & Zhang, (1991) \\
\hline MSQ-1 & - & 0.5 & 60 & 80 & 35 & 150 & 0.2 & 20 & $\begin{array}{l}\text { Marine } \\
\text { sediment }\end{array}$ \\
\hline MSQ-2 & - & 1.5 & 130 & 150 & 100 & 350 & 0.5 & 65 & $\begin{array}{l}\text { Quality } \\
\text { standards }\end{array}$ \\
\hline MSQ-3 & - & 5.0 & 250 & 270 & 200 & 600 & 1.0 & 93 & $\begin{array}{l}\text { (GB18668- } \\
2002)\end{array}$ \\
\hline
\end{tabular}

$57.55 \%, \quad 15.50 \%, \quad 15.60,29.33,18.78, \quad 38.20$, and $7.79 \%$, respectively. The results demonstrated that the concentrations of heavy metals $(\mathrm{Cd}, \mathrm{Pb}, \mathrm{Cu}, \mathrm{Hg}, \mathrm{As})$ were relatively discrete in spring.

Compared with the marine sediment quality standards (GB18668-2002) (China), the concentration of $\mathrm{Cr}$ (excess rate: $35 \%$ ) in spring and copper (excess rate: $4.76 \%$ ) and zinc (excess rate: $4.76 \%$ ) in autumn exceeded the primary standard criteria (MSQ-1), and all the others were below the primary standard criteria. The mean and standard deviations of all the heavy metals in the research area and other relevant regions were calculated and are displayed in Table 2. The average concentration of these examined metals in the research area was higher than that in other related regions in spring, with the exception of mangrove areas and Beibu Bay. However, in autumn, all examined heavy metals were in the mean interval of other relevant areas except $\mathrm{Zn}, \mathrm{Pb}$, and $\mathrm{Cu}$.

\section{The Spatial Distribution of Heavy Metals}

The spatial distributions of heavy metal concentrations in the research region were displayed in Figures 3 and 4, and they showed similar overall patterns. The highest concentrations occurred near Chunzhou and Dazhou Island in spring and autumn, decreasing to the periphery (except for As in spring). $\mathrm{Cd}, \mathrm{Zn}$, and $\mathrm{Hg}$ showed the same spatial distribution in both spring and autumn, with their highest values occurring near Dazhou Island, especially east of Yalin Bay. The lowest concentrations occurred in the northeastern part of the research area. The maximum values of As occurred in the northeastern part of the study area in spring, and in the central regions in autumn, which was different than observed in a previous study (Dou et al., 2013). Since there is no major rivers discharge into Daya Bay and human activities are concentrated in the vicinity of the continental shelf, higher concentrations of these heavy metals are expected to be inside 

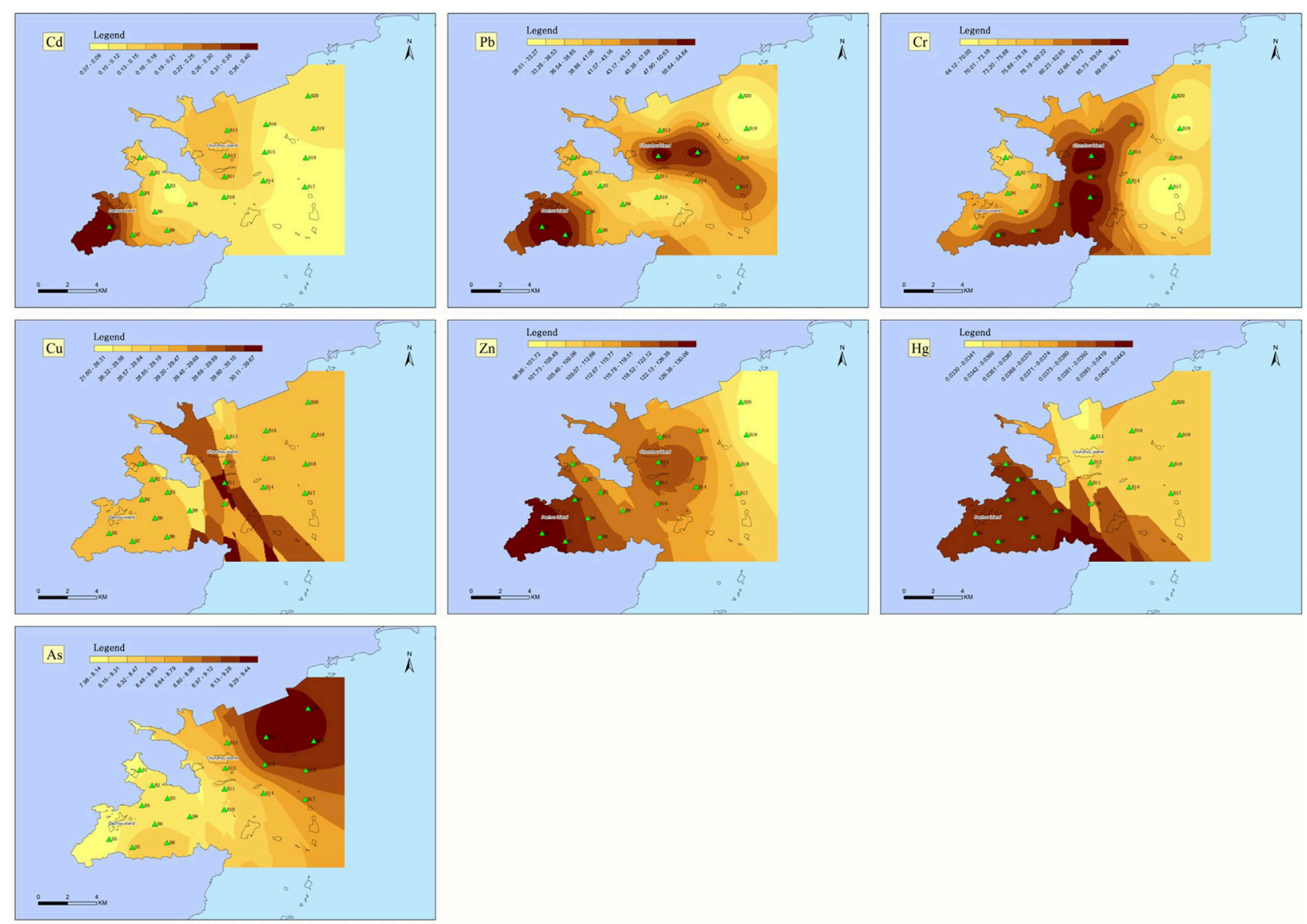

FIGURE 3 | Spatial distribution of heavy metals in surface sediments of the study area in spring.

of the bay (Yu et al., 2010). In general, all heavy metals changed unobviously in spring and autumn except As, which might be due to the small seasonal variation of outlet input volume, and the significant changes of As in spring and autumn might be related to the influence of atmospheric deposition (Lü et al., 2018). Due to the southerly and easterly wind blowing in spring and the northerly wind in autumn in Daya Bay, precipitation in the bay is greater in summer and autumn, explaining the greater seasonal variation in As.

\section{Heavy Metals Contamination and Their Ecological Risk}

As illustrated in Figure 5, the $I_{g e o}$ values of the measured heavy metals were: 0.79 to 3.37 (average 1.57) for $\mathrm{Cd},-0.24$ to 0.74 (average 0.33 ) for $\mathrm{Pb}, 0.89$ to 1.59 (average 1.24) for $\mathrm{Cr}, 0.43$ to 3.09 (average 1.37) for $\mathrm{Cu}, 1.28$ to 2.12 (average 1.82) for $\mathrm{Zn},-0.24$ to 1.98 (average 1.12) for $\mathrm{Hg}, 0.78$ to 1.49 (average 1.12) for As in spring, and 0.30 to 2.74 (average 1.10) for $\mathrm{Cd},-0.46$ to 0.57 (average 0.22 ) for $\mathrm{Pb},-0.48$ to 0.89 (average 0.63 ) for $\mathrm{Cr}, 0.31$ to 1.86 (average 1.21) for $\mathrm{Cu}, 1.47$ to 2.49 (average 1.82) for $\mathrm{Zn}, 0.28$ to 1.93 (average 1.03) for $\mathrm{Hg}, 0.82$ to 1.14 (average 0.97 ) for As in autumn. These values show that there was a significant difference between spring and autumn. For these metals, their average pollution level can be ranked in descending order in spring: $\mathrm{Zn}>\mathrm{Cd}>\mathrm{Cu}>\mathrm{Cr}>\mathrm{As}=\mathrm{Hg}>\mathrm{Pb}$, while in autumn the order is $\mathrm{Zn}>\mathrm{Cu}>\mathrm{Cd}>\mathrm{Hg}>\mathrm{As}>\mathrm{Cr}>\mathrm{Pb}$. According to Müller's (Müller, 1981) criteria, the $I_{\text {geo }}$ values of heavy metals indicated unpolluted to moderate pollution in the study area. However, the $I_{\text {geo }}$ values during spring indicated a higher level of pollution than those in autumn, especially for $\mathrm{Cr}$ and As. Previous studies (Zhao et al., 2016) have demonstrated that the mean $I_{\text {geo }}$ values for $\mathrm{Cd}$, $\mathrm{Cr}, \mathrm{Cu}, \mathrm{Hg}$, and $\mathrm{Zn}$ were less than zero $\left(I_{\text {geo }}<0\right)$, indicating limited pollution in Daya Bay and the adjacent shelf. In contrast, the mean $I_{\text {geo }}$ values for $\mathrm{As}$ and $\mathrm{Pb}$ reached 0.07 and 0.49 , respectively, suggesting moderate pollution levels by these metals in the study area in 2008. The results showed that the environmental quality of sediments in Daya Bay deteriorated. In general, the distribution trends in spring and autumn were very similar, which might be due to the effect of sewage on heavy metals being greater than that of river-derived pollutants.

Risk assessment of heavy metals in sediments is particularly important for environmental management (Qu et al., 2016). The $R I$ values fluctuated greatly, and ranged from 225.86 to 734.20 in spring, and from 196.69 to 567.52 in autumn, respectively. As shown in Figure 6, the highest ecological risk of all heavy metals 

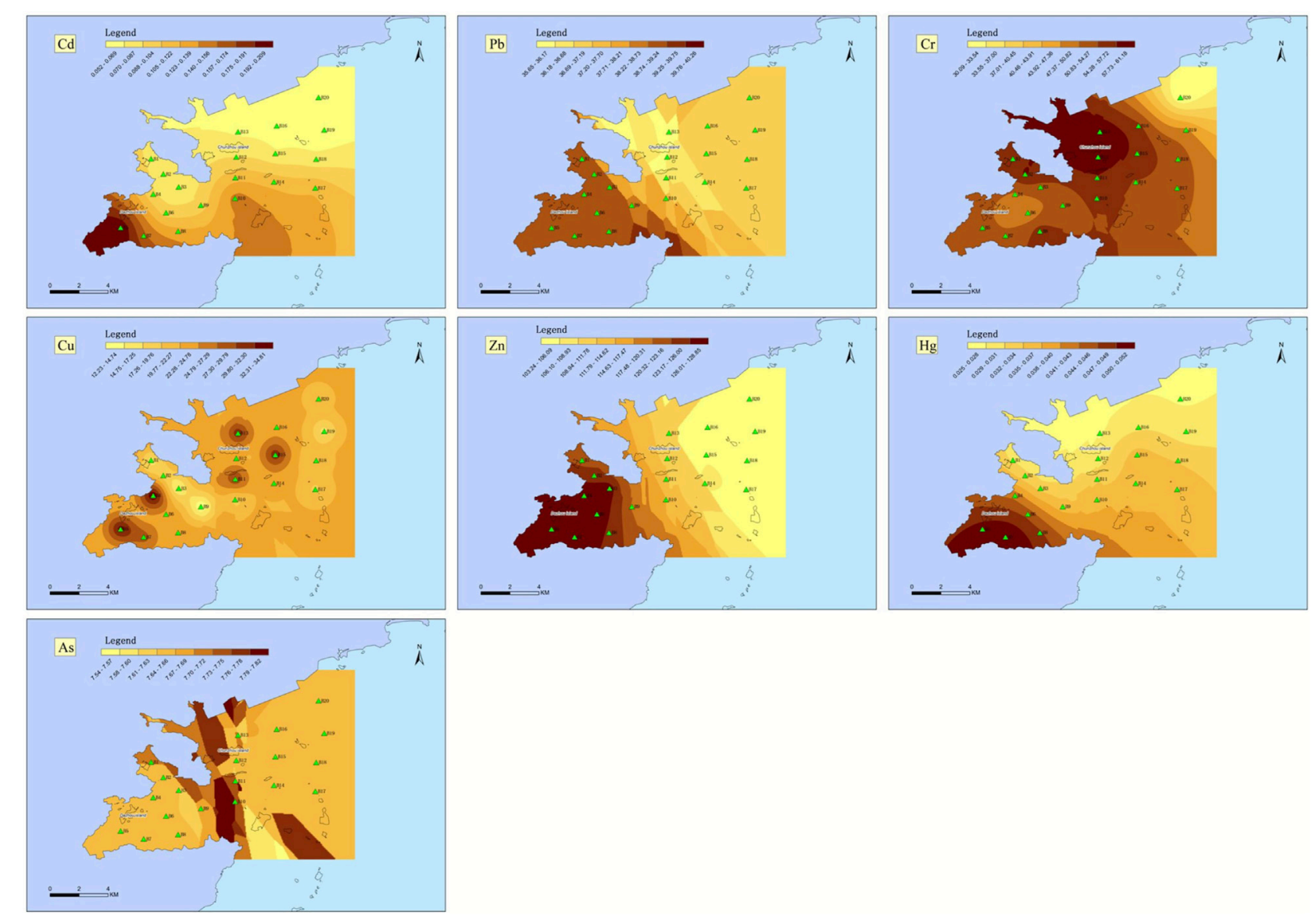

FIGURE 4 | Spatial distribution of heavy metals in surface sediments of the study area in autumn.
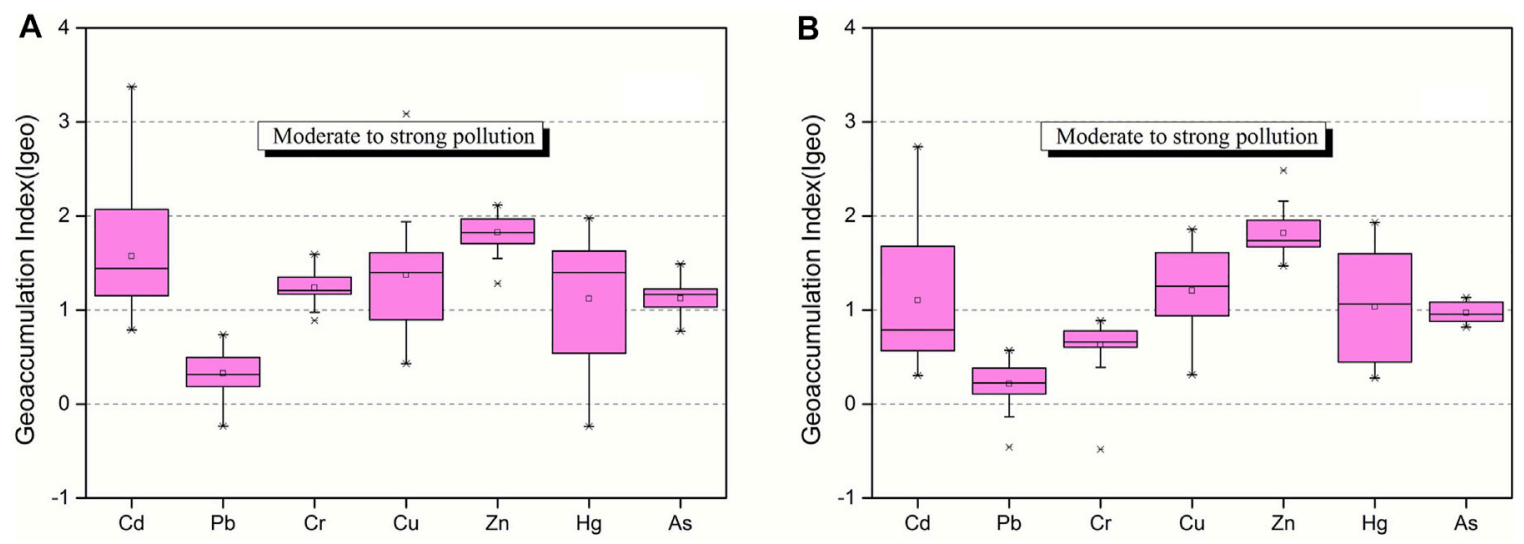

FIGURE 5 | Geoaccumulation index $\left(I_{\text {geo }}\right)$ of heavy metals in surface sediments during spring (A) and autumn (B).

occurred in the area near Dazhou Island in both spring and autumn, decreasing to the periphery. However, the $R I$ values in spring were obviously higher than those in autumn. On the basis of Hakanson's classification (Hakanson, 1980), the RI values of the heavy metals in our study suggest that most sites have a moderate ecological risk or a considerable ecological risk, and very few had a high ecological risk. Overall, the distribution trend of $R I$ in spring and autumn was very similar to the $I_{g e o}$ evaluation results, and the impact of outlets on heavy metals is greater than that of terrestrial pollutants, i.e., rivers. However, the $R I$ values in 

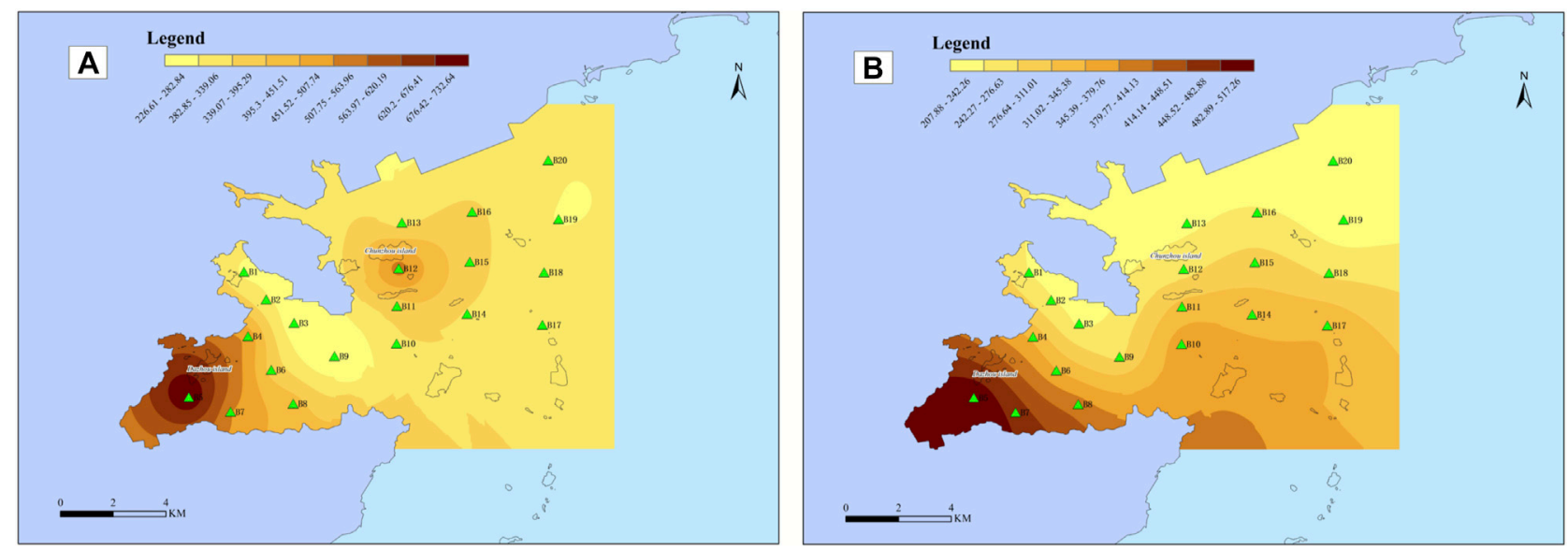

FIGURE 6 | The potential ecological risk index (R) of heavy metals in surface sediments during spring (A) and autumn (B).

TABLE 3 | Heavy metal communality of rotated component matrix for $\mathrm{Cd}, \mathrm{Pb}, \mathrm{Cr}$, $\mathrm{Cu}, \mathrm{Zn}, \mathrm{Hg}$, and As of surface sediments in Daya Bay.

\begin{tabular}{lcc} 
& \multicolumn{2}{c}{ Component } \\
\cline { 2 - 3 } & $\mathbf{1}$ & $\mathbf{2}$ \\
\hline $\mathrm{Cd}$ & 0.640 & 0.797 \\
$\mathrm{~Pb}$ & 0.860 & 0.240 \\
$\mathrm{Cr}$ & 0.206 & -0.156 \\
$\mathrm{Cu}$ & 0.717 & 0.046 \\
$\mathrm{Zn}$ & 0.754 & 0.292 \\
$\mathrm{As}$ & 0.810 & -0.878 \\
$\mathrm{Hg}$ & -0.071 & -0.057 \\
$\%$ of variance & 45.45 & 27.22 \\
\% of cumulative & 45.45 & 68.22
\end{tabular}

Notes: 1) Extraction method: principal component analysis; 2) Rotation method: varimax with Kaiser normalization; 3) Rotation converged in 3 iterations.

spring were significantly higher than those in autumn. This may be due to the smaller sediment size in spring and more heavy metals being adsorbed.

\section{Identification of Heavy Metals Sources}

Pearson correlation analysis (Figure 7) indicated that there were no relatively significant correlations between heavy metals (Cd, $\mathrm{Pb}, \mathrm{Cr}, \mathrm{Cu}, \mathrm{Zn}, \mathrm{Hg}, \mathrm{As}$ ) and the gravel, sand, silt, and clay measurements. A large number of studies (Swarnalatha et al., 2014; Han et al., 2017; Xu et al., 2018) have shown that changes in heavy metal contents are closely related to changes in sediment particle size. An increase in clay minerals, and their specific surface area, results in increased surface free energy and therefore greater heavy metal adsorption ( $\mathrm{Lu}$ et al., 2017; Naifar et al., 2018). Moreover, organic matter is highly related to heavy metals in the aquatic environment through adsorption and complexion (Dou et al., 2013; Liu et al., 2017). The results of the Pearson correlation matrix show that there is a significant correlation between total organic carbon (TOC) and $\mathrm{Cd}, \mathrm{Pb}, \mathrm{Hg}$, and $\mathrm{Zn}$. Moreover, As and $\mathrm{Cr}$

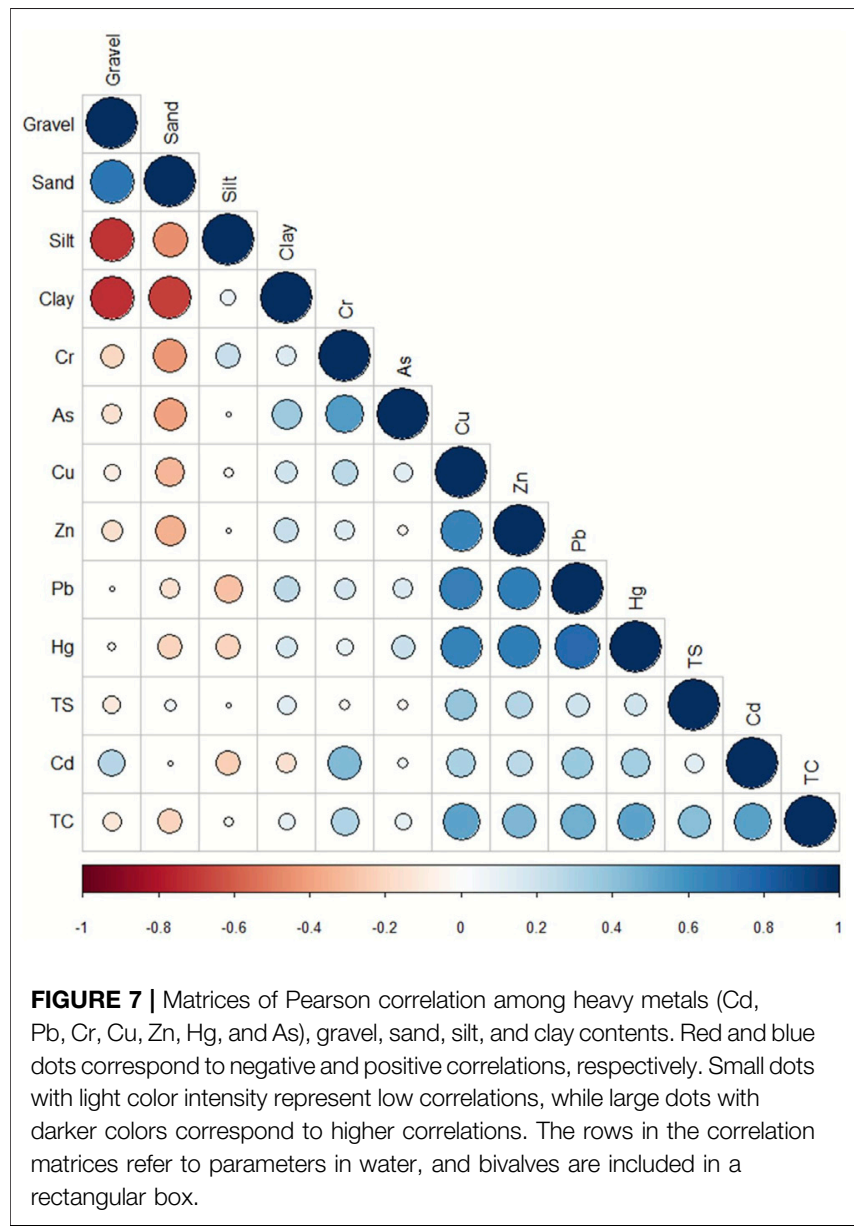

were also strongly correlated, suggesting that they might have a common source.

Principal component analysis (PCA) processed by SPSS 22.0 was used in this research. The rotated component matrices of 


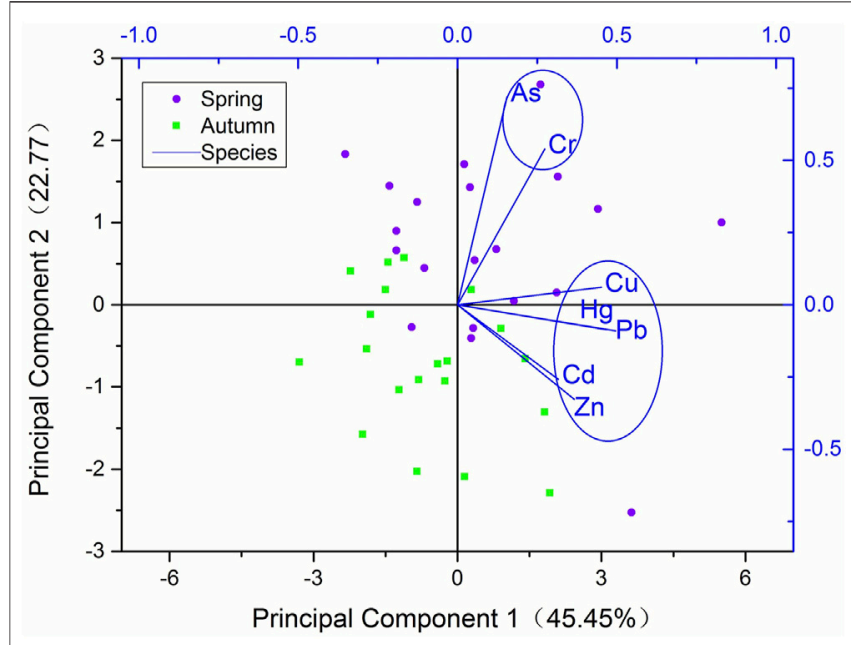

FIGURE 8 | Component scores for the first two principal components (PC1 vs. PC2).

the PCA are shown in Table 3. The Kaiser-Meyer-Olkin (KMO) and Bartlett's results were 0.650 and $105.62(\mathrm{df}=21$, Sig $\mathrm{b}<$ 0.001 ), respectively, suggesting that PCA might be useful in reducing the dimensionality. The PCA indicated that the proportion of the first two principal components among the total variants was 68.22 (Figure 8). The first principal component (PC1) with high loadings of $\mathrm{Cu}, \mathrm{Cr}, \mathrm{Zn}, \mathrm{Hg}$, and $\mathrm{Pb}$ accounted for $45.45 \%$ of the total variance, suggesting that they might have similar sources. Concentrations of $\mathrm{Cu}, \mathrm{Cr}, \mathrm{Zn}$, $\mathrm{Hg}$, and $\mathrm{Pb}$ were higher than their corresponding background values, and they were also present at moderate pollution levels based on their $I_{g e o}$ values, demonstrating that these five heavy metals were moderately affected by anthropogenic activities. The second principal component (PC2) accounted for $22.77 \%$ of the total variance, with the strongest loadings from As. According to spatial interpolation analysis, As is mainly affected by atmospheric deposition, and PC2 may represent natural sources.

Before clustering, the data were processed with a single factor pollution index to reduce the error, so that the clustering result was closer to reality. Cluster analysis was conducted to examine the relationships among variables (heavy metals in the surface sediment) and sample sites (Figure 1). As shown in Figure 9A, in spring, the left vertical dendrogram (left side of the box) exhibited clustering of the sampling sites in line with heavy metal concentrations in the surface sediment. The horizontal dendrogram indicated clustering of heavy metals in line with their likenesses. In the vertical dendrogram, all the sampling sites in Daya Bay were divided into four clusters. Cluster I was composed of 8 sampling sites (B11, B13, B19, B20, B3, B9, B1, B2), cluster II contained 10 sample stations (B8, B4, B7, B15, B16, B17, B18, B6, B10, B14), cluster III contained 1 sampling site (B5), and the last site (B12) near Chunzhou Island was located in cluster IV. The results indicated that the distribution of the heavy metals was somewhat different in the 20 sampling sites. Obviously, there were distinct common characteristics in each cluster. In cluster $\mathrm{I}, \mathrm{Pb}, \mathrm{Cu}$, and $\mathrm{Hg}$ in sites B19, B20, B3, B9, B1, and B2 had relatively low concentrations. These stations should have high concentrations because they are near waterways or sewage outfalls. This phenomenon might be due to the negative impact that of humans have on the environment, such as the regular cleaning of waterways (Jiang et al., 2007). In clusters II and III, all heavy metal concentrations were high, especially the $\mathrm{Cd}, \mathrm{Cu}$, and $\mathrm{Hg}$ concentrations. According to the spatial distribution diagram, these sites are mainly concentrated in the vicinity of Yalin Bay, suggesting that the high concentrations of $\mathrm{Cd}, \mathrm{Cu}$, and $\mathrm{Hg}$ were related to shellfish farming. Similar to cluster III and cluster IV, all their concentrations were also relatively higher, but $\mathrm{Cu}$ was notably higher. This might be due to the inflow of rivers which have plenty of industrial activities upstream, such as the Danao River and Xiachong River. Industrial activities, including the chemical production industry, cotton industry, paper industry, dyeing

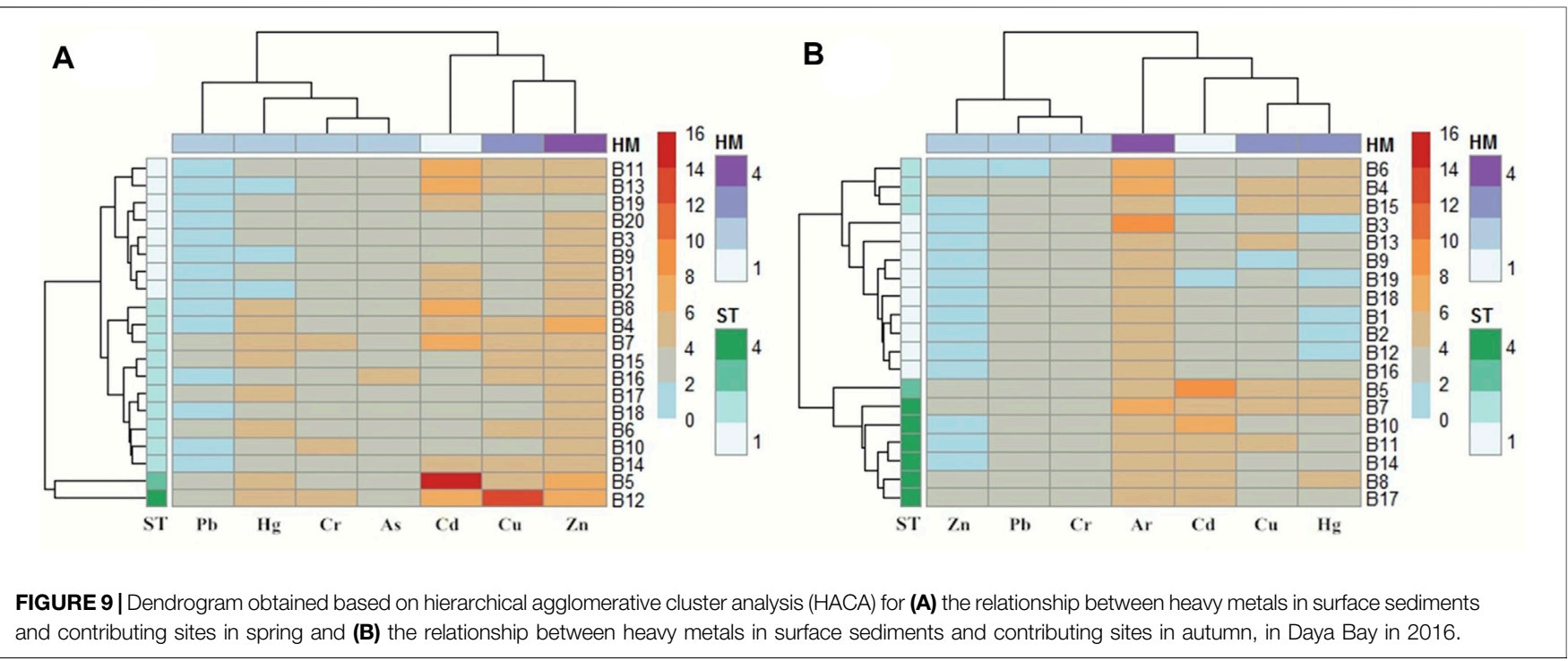


industry, and metalworking industry, may augment the concentrations of $\mathrm{Cu}, \mathrm{Pb}$, and $\mathrm{Zn}$ (Liang et al., 2018). There were 4 different clusters for the heavy metals in the horizontal dendrogram. Cluster I incorporated $\mathrm{Cd}$, cluster II included $\mathrm{Pb}$, $\mathrm{Cr}$, As, and $\mathrm{Hg}$, cluster III was made up of $\mathrm{Cu}$, and the only member of cluster IV was $\mathrm{Zn}$.

As shown in Figure 9B, in the vertical dendrogram, the Daya Bay sampling sites can be divided into four clusters in autumn, which were the same as those in spring. Cluster I was composed of nine sampling sites (B3, B13, B9, B19, B18, B20, B1, B2, B12, $\mathrm{B} 16)$, cluster II contained three sample sites (B6, B4, B15), cluster III contained one sampling site (B5), and finally, the remaining sites (B10, B11, B14, B8, B17) were included in cluster IV. For cluster I and cluster 3, the above sampling site clustering analysis in spring can also be applied in autumn. There were 4 different clusters for the heavy metals in the horizontal dendrogram. Cluster I consisted of Cd, cluster II included $\mathrm{Pb}, \mathrm{Cr}$, and $\mathrm{Zn}$, cluster III was made up of $\mathrm{Hg}$ and $\mathrm{Cu}$, and only member of cluster IV was As. This result is different from the results in spring, which also proves that As is affected by atmospheric deposition.

\section{CONCLUSION}

In spring and autumn of 2016, grain size and heavy metal $(\mathrm{Cd}, \mathrm{Pb}$, $\mathrm{Cr}, \mathrm{Cu}, \mathrm{Zn}, \mathrm{Hg}$, and $\mathrm{As}$ ) concentrations were analyzed in surface sediment samples collected from a marine protected area with larval economic fish and shrimp populations in Daya Bay. For the physicochemical properties of the sediments, generally, the surface sediments primarily consisted of silt and clay in spring and autumn, and the average particle size in spring was smaller than that in autumn. For the heavy metal analysis, all the heavy metal concentrations were below the primary standard criteria, except for the concentrations of $\mathrm{Cr}$ in spring and $\mathrm{Cu}$ and $\mathrm{Zn}$ at autumn in several sampling stations. The spatial distributions of heavy metal concentrations in the study area were the same in spring and autumn, which might be due to the small seasonal variation in sewage discharge. The highest heavy metal values

\section{REFERENCES}

Dou, Y., Li, J., Zhao, J., Hu, B., and Yang, S. (2013). Distribution, Enrichment and Source of Heavy Metals in Surface Sediments of the Eastern Beibu Bay, South China Sea. Mar. Pollut. Bull. 67 (1-2), 137-145. doi:10.1016/ j.marpolbul.2012.11.022

Ervin, J., Mulongoy, K. J., Lawrence, K., Game, E., Sheppard, D., Bridgewater, P., et al. (2010). Making Protected Areas Relevant: A Guide to Integrating Protected Areas into Wider Landscapes, Seascapes and Sectoral Plans and Strategies. Convent. Biol. Divers.

Feng, J., Zhu, X., Wu, H., Ning, C., and Lin, G. (2017). Distribution and Ecological Risk Assessment of Heavy Metals in Surface Sediments of a Typical Restored Mangrove-Aquaculture Wetland in Shenzhen, China. Mar. Pollut. Bull. 124 (2), 1033-1039. doi:10.1016/j.marpolbul.2017.01.004

Gaines, S. D., White, C., Carr, M. H., and Palumbi, S. R. (2010). Designing marine reserve Networks for Both Conservation and Fisheries Management. Proc. Natl. Acad. Sci. 107 (43), 18286-18293. doi:10.1073/pnas.0906473107 were found near Dazhou Island, especially east of Yalin Bay, and the lowest concentrations occurred in the northeastern part of the research area. Most of sites had a moderate ecological risk or a considerable ecological risk level, and very few had high ecological risk levels. Heavy metals are mainly derived from natural sources such as human activities and atmospheric input, and man-made sources are mainly affected negatively by human activities, such as sewage outlets, channel dredging, and shellfish farming.

\section{DATA AVAILABILITY STATEMENT}

The original contributions presented in the study are included in the article/Supplementary Material. Further inquiries can be directed to the corresponding authors.

\section{AUTHOR CONTRIBUTIONS}

HW wrote the article and did the laboratory analysis. HW and $\mathrm{HH}$ contributed to the field analysis, while the latter also conceptualized the research. ZF, ZK, YY, and HL provided conceptual and editorial inputs on the manuscript and discussed field methodology. All authors contributed to the article and approved the submitted version.

\section{FUNDING}

This work was supported by the Shanghai Pujiang Program and the Project of Science and Technology of Guangdong Province (grant number 2016A020222024)

\section{ACKNOWLEDGMENTS}

We are also grateful to reviewers for helpful comments on the manuscript.

Gu, Y.-G. (2018). Heavy Metal Fractionation and Ecological Risk Implications in the Intertidal Surface Sediments of Zhelin Bay, South China. Mar. Pollut. Bull. 129, 905-912. doi:10.1016/ j.marpolbul.2017.10.047

Gu, Y.-G., Wang, X.-N., Lin, Q., Du, F.-Y., Ning, J.-J., Wang, L.-G., et al. (2016). Fuzzy Comprehensive Assessment of Heavy Metals and Pb Isotopic Signature in Surface Sediments from a bay under Serious Anthropogenic Influences: Daya Bay, China. Ecotoxicology Environ. Saf. 126, 38-44. doi:10.1016/ j.ecoenv.2015.12.011

Hakanson, L. (1980). An Ecological Risk index for Aquatic Pollution control.a Sedimentological Approach. Water Res. 14 (8), 975-1001. doi:10.1016/00431354(80)90143-8

Han, D., Cheng, J., Hu, X., Jiang, Z., Mo, L., Xu, H., et al. (2017). Spatial Distribution, Risk Assessment and Source Identification of Heavy Metals in Sediments of the Yangtze River Estuary, China. Mar. Pollut. Bull. 115 (1-2), 141-148. doi:10.1016/j.marpolbul.2016.11.062

Jiang, B., Zheng, H.-l., Huang, G.-q., Ding, H., Li, X.-g., Suo, H.-t., et al. (2007). Characterization and Distribution of Polycyclic Aromatic Hydrocarbon in 
Sediments of Haihe River, Tianjin, China. J. Environ. Sci. 19 (3), 306-311. doi:10.1016/S1001-0742(07)60050-3

Kang, X., Song, J., Yuan, H., Duan, L., Li, X., Li, N., et al. (2017). Speciation of Heavy Metals in Different Grain Sizes of Jiaozhou Bay Sediments: Bioavailability, Ecological Risk Assessment and Source Analysis on a Centennial Timescale. Ecotoxicology Environ. Saf. 143, 296-306. doi:10.1016/ j.ecoenv.2017.05.036

Karim, L. R., and Williams, E. S. (2015). Accumulation of Heavy Metals in the Surface Water of Asthamudi lake, Kollam, Kerala. Nat. Environ. Pollut. Technology 14 (2), 431-434.

Liang, X., Song, J., Duan, L., Yuan, H., Li, X., Li, N., et al. (2018). Source Identification and Risk Assessment Based on Fractionation of Heavy Metals in Surface Sediments of Jiaozhou Bay, China. Mar. Pollut. Bull. 128, 548-556. doi:10.1016/j.marpolbul.2018.02.008

Liang, Y., and Wong, M. H. (2003). Spatial and Temporal Organic and Heavy Metal Pollution at Mai Po Marshes Nature Reserve, Hong Kong. Chemosphere 52 (9), 1647-1658. doi:10.1016/s0045-6535(03)00505-8

Liu, X., Zhang, L., and Zhang, L. (2017). Concentration, Risk Assessment, and Source Identification of Heavy Metals in Surface Sediments in Yinghai: A Shellfish Cultivation Zone in Jiaozhou Bay, China. Mar. Pollut. Bull. 121 (1-2), 216-221. doi:10.1016/j.marpolbul.2017.05.063

Loska, K., Cebula, J., Pelczar, J., Wiechuła, D., and Kwapuliński, J. (1997). Use of Enrichment, and Contamination Factors Together with Geoaccumulation Indexes to Evaluate the Content of $\mathrm{Cd}, \mathrm{Cu}$, and $\mathrm{Ni}$ in the Rybnik Water Reservoir in Poland. Water Air Soil Pollut. 93 (1-4), 347-365. doi:10.1007/ bf02404766

Lü, J., Jiao, W.-B., Qiu, H.-Y., Chen, B., Huang, X.-X., and Kang, B. (2018). Origin and Spatial Distribution of Heavy Metals and Carcinogenic Risk Assessment in Mining Areas at You'xi County Southeast China. Geoderma 310, 99-106. doi:10.1016/j.geoderma.2017.09.016

Lu, J., Li, A., and Huang, P. (2017). Distribution, Sources and Contamination Assessment of Heavy Metals in Surface Sediments of the South Yellow Sea and Northern Part of the East China Sea. Mar. Pollut. Bull. 124 (1), 470-479. doi:10.1016/j.marpolbul.2017.07.007

Müller, G. (1981). Die Schwermetallbelstung der sedimente des Neckars und seiner Nebenflusse: Eine Bestandsaufnahme.

Müller, G. (1979). Schwermetalle in den sedimenten des Rheins-Veräderungen seit.

Naifar, I., Pereira, F., Zmemla, R., Bouaziz, M., Elleuch, B., and Garcia, D. (2018). Spatial Distribution and Contamination Assessment of Heavy Metals in marine Sediments of the Southern Coast of Sfax, Gabes Gulf, Tunisia. Mar. Pollut. Bull. 131 (Pt A), 53-62. doi:10.1016/j.marpolbul.2018.03.048

Nel, M. A., Rubidge, G., Adams, J. B., and Human, L. R. D. (2020). Rhizosediments of Salicornia Tegetaria Indicate Metal Contamination in the Intertidal Estuary Zone. Front. Environ. Sci. 8. doi:10.3389/fenvs.2020.572730

Pan, D., Ding, X., Han, H., Zhang, S., and Wang, C. (2020). Species, SpatialTemporal Distribution, and Contamination Assessment of Trace Metals in Typical Mariculture Area of North China. Front. Mar. Sci. 7. doi:10.3389/ fmars.2020.552893

Qian, L., Song, J., Wang, E., Hao, H., Zhang, J., and Wang, Y. (2014). Economic Growth and Pollutant Emissions in China: a Spatial Econometric Analysis. Stochastic Environ. Res. Risk Assess. 28 (2), 429-442.

Qu, C., Li, B., Wu, H., Wang, S., and Li, F. (2016). Probabilistic Ecological Risk Assessment of Heavy Metals in Sediments from China's Major Aquatic Bodies. Stochastic Environ. Res. Risk Assess. 30 (1), 271-282.

Ranjbar Jafarabadi, A., Riyahi Bakhtiyari, A., Shadmehri Toosi, A., and Jadot, C. (2017). Spatial Distribution, Ecological and Health Risk Assessment of Heavy Metals in marine Surface Sediments and Coastal Seawaters of Fringing Coral
Reefs of the Persian Gulf, Iran. Chemosphere 185, 1090-1111. doi:10.1016/ j.chemosphere.2017.07.110

Shakouri, A., and Gheytasi, H. (2018). Bioaccumulation of Heavy Metals in Oyster (Saccostrea Cucullata) from Chabahar bay Coast in Oman Sea: Regional, Seasonal and Size-dependent Variations. Mar. Pollut. Bull. 126, 323-329. doi:10.1016/j.marpolbul.2017.11.012

Swarnalatha, K., Letha, J., and Ayoob, S. (2014). Effect of Seasonal Variations on the Surface Sediment Heavy Metal Enrichment of a lake in South India. Environ. Monit. Assess. 186 (7), 4153-4168. doi:10.1007/s10661-014-3687-8

Tian, K., Huang, B., Xing, Z., and Hu, W. (2017). Geochemical Baseline Establishment and Ecological Risk Evaluation of Heavy Metals in Greenhouse Soils from Dongtai, China. Ecol. Indicators 72, 510-520. doi:10.1016/j.ecolind.2016.08.037

Xu, F., Hu, B., Yuan, S., Zhao, Y., Dou, Y., Jiang, Z., et al. (2018). Heavy Metals in Surface Sediments of the continental Shelf of the South Yellow Sea and East China Sea: Sources, Distribution and Contamination. Catena 160, 194-200. doi:10.1016/j.catena.2017.09.022

Yu, X., Yan, Y., and Wang, W.-X. (2010). The Distribution and Speciation of Trace Metals in Surface Sediments from the Pearl River Estuary and the Daya Bay, Southern China. Mar. Pollut. Bull. 60 (8), 1364-1371. doi:10.1016/ j.marpolbul.2010.05.012

Zhang, P., Hu, R., Zhu, L., Wang, P., Yin, D., and Zhang, L. (2017a). Distributions and Contamination Assessment of Heavy Metals in the Surface Sediments of Western Laizhou Bay: Implications for the Sources and Influencing Factors. Mar. Pollut. Bull. 119 (1), 429-438. doi:10.1016/j.marpolbul.2017.03.046

Zhang, Y. (1991). A Background Value Study on Heavy Metals in the Sediments of Daya bay. Trapic Oceanology 10 (3), 76-80.

Zhang, Y., Chu, C., Li, T., Xu, S., Liu, L., and Ju, M. (2017b). A Water Quality Management Strategy for Regionally Protected Water through Health Risk Assessment and Spatial Distribution of Heavy Metal Pollution in 3 marine Reserves. Sci. Total Environ. 599-600, 721-731. doi:10.1016/ j.scitotenv.2017.04.232

Zhao, G., Ye, S., Yuan, H., Ding, X., and Wang, J. (2016). Distribution and Contamination of Heavy Metals in Surface Sediments of the Daya Bay and Adjacent Shelf, China. Mar. Pollut. Bull. 112 (1-2), 420-426. doi:10.1016/ j.marpolbul.2016.07.043

Zhu, L., Xu, J., Wang, F., and Lee, B. (2011). An Assessment of Selected Heavy Metal Contamination in the Surface Sediments from the South China Sea before 1998. J. Geochemical Exploration 108 (1), 1-14. doi:10.1016/j.gexplo.2010.08.002

Conflict of Interest: The authors declare that the research was conducted in the absence of any commercial or financial relationships that could be construed as a potential conflict of interest.

Publisher's Note: All claims expressed in this article are solely those of the authors and do not necessarily represent those of their affiliated organizations, or those of the publisher, the editors, and the reviewers. Any product that may be evaluated in this article, or claim that may be made by its manufacturer, is not guaranteed or endorsed by the publisher.

Copyright $\odot 2021$ Wang, Fan, Kuang, Yuan, Liu and Huang. This is an open-access article distributed under the terms of the Creative Commons Attribution License (CC $B Y)$. The use, distribution or reproduction in other forums is permitted, provided the original author(s) and the copyright owner(s) are credited and that the original publication in this journal is cited, in accordance with accepted academic practice. No use, distribution or reproduction is permitted which does not comply with these terms. 